07

\title{
Исследование связи степени дефектности светоизлучающих наногетероструктур зеленых InGaN/GaN-светодиодов с величиной порогового тока
}

\author{
(C) В.А. Сергеев ${ }^{1,2}$, И.В. Фролов ${ }^{1, \uparrow}$, О.А. Радаев ${ }^{1,2}$ \\ ${ }^{1}$ Ульяновский фрилиал Института радиотехники и электроники \\ им. В.А. Котельникова РАН, Ульяновск \\ ${ }^{2}$ Ульяновский государственный технический университет, Ульяновск \\ ฯ E-mail: ilya-frolov88@mail.ru
}

\section{Поступило в Редакцию 26 мая 2016 г.}

Показана возможность использования значений порогового тока для оценки качества светоизлучающих наногетероструктур зеленых InGaN/GaN-светодиодов. Определено, что значения порогового тока коррелируют со значениями тока, при котором наблюдается максимум токовой зависимости внешней квантовой эффективности светодиода. Показано, что при испытаниях в режиме постоянного тока светодиоды с большими значениями порогового тока деградируют быстрее, чем светодиоды с малыми значениями порогового тока.

DOI: 10.21883/PJTF.2017.04.44302.16344

С целью повышения надежности технических устройств и систем с использованием InGaN/GaN-светодиодов активно разрабатываются способы и средства неразрушающего контроля их качества $[1,2]$. Малоизученным, но весьма информативным параметром, дающим представление о качестве гетероструктуры светодиода, является пороговый ток. Для лазеров этим термином обозначают ток, при котором излучение из спонтанного переходит в индуцированное. Для светодиодов под данным термином понимают минимальный ток, при котором удается зарегистрировать излучение $[3,4]$. Пороговый ток характеризует потери на безызлучательную рекомбинацию в системе дефектов, пронизывающих активную область светодиода [4], следовательно, характеристики выборочных распределений светодиодов по значениям порогового тока 


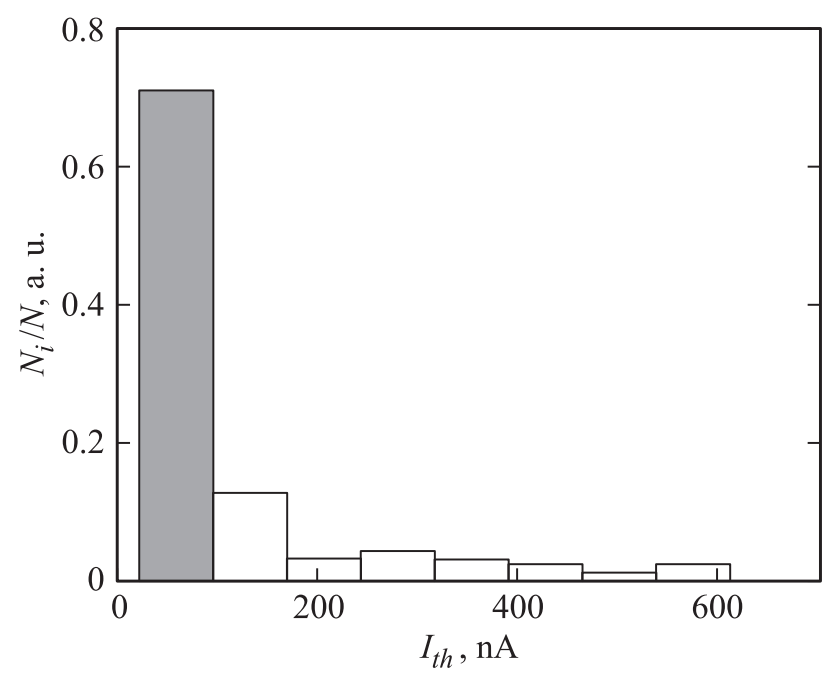

Рис. 1. Гистограмма распределения группы светодиодов из $N=100$ штук по величине порогового тока.

могут быть использованы для оценки качества светоизлучающей гетероструктуры.

В данной работе представлены результаты исследования зеленых светодиодов InGaN/GaN типа ARL-5215PGC фирмы Arlight в количестве $N=100$ штук со следующими параметрами: длина волны в максимуме спектра излучения $\lambda_{\max }=525 \mathrm{~nm}$, максимальный постоянный рабочий ток $I_{\max }=30 \mathrm{~mA}$, размеры кристалла $270 \times 320 \mu \mathrm{m}$.

Измерение порогового тока светодиодов выполнено на автоматизированной установке [5] по алгоритму, представленному в [6]. Измерение мощности излучения светодиодов выполнялось с помощью интегрирующей сферы ТКА-КК1.

Результаты измерений показали, что значения порогового тока $I_{t h}$ светодиодов исследованного типа (при температуре окружающей среды $T=300 \mathrm{~K}$ ) лежат в пределах $21-607 \mathrm{nA}$. Гистограмма распределения светодиодов по величине порогового тока $I_{t h}$ представлена на рис. 1. Среднее значение порогового тока по выборке составляет $110 \mathrm{nA}$, среднеквадратическое отклонение - $113 \mathrm{nA}$. Близость значений оценки

Письма в ЖТФ, 2017, том 43, вып. 4 


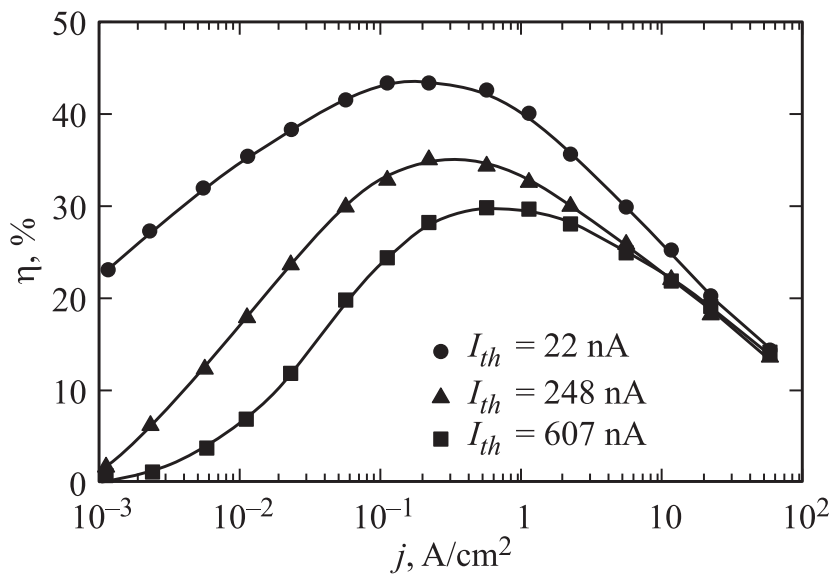

Рис. 2. Зависимость внешней квантовой эффективности от плотности тока для трех светодиодов с различными значениями порогового тока.

математического ожидания и среднеквадратического отклонения свидетельствует об экспоненциальном законе распределения светодиодов по величине порогового тока [7]. В литературе отмечается, что для полупроводниковых изделий характерно экспоненциальное распределение по плотности дефектов [8,9]. Следовательно, экспоненциальное распределение светодиодов по величине порогового тока косвенно указывает на связь этого параметра с плотностью дефектов в активной области гетероструктуры. При этом 72 светодиода, характеризующиеся меньшими концентрациями дефектов в активной области, находятся в первом интервале гистограммы распределения, который выделен на рис. 1 серым фоном, т.е. имеют значения порогового тока в диапазоне 21-90 nA, а у остальных 28 образцов значения порогового тока лежат в диапазоне 90-607 nA.

Для подтверждения предположения о связи порогового тока с плотностью дефектов в активной области гетероструктуры исследовалась взаимозависимость между уровнем порогового тока и характером зависимости внешней квантовой эффективности светодиода от плотности тока $\eta(j)$. На рис. 2 представлены графики зависимости внешней квантовой эффективности от плотности тока для трех светодиодов

Письма в ЖТФ, 2017, том 43, вып. 4 
исследованной выборки, характеризующихся различными значениями порогового тока $I_{t h}$. Из рисунка видно, что наиболее заметно разброс значений внешней квантовой эффективности светодиодов проявляется в диапазоне малых плотностей тока, соответствующих участку роста функции $\eta(j)$. При плотностях тока, соответствующих участку спада токовой зависимости внешней квантовой эффективности, светодиоды имеют близкие значения внешней квантовой эффективности. Согласно модели, представленной в [10], это объясняется следующим. При малых плотностях тока центры безызлучательной рекомбинации, присутствующие в активной области светодиода, эффективно захватывают инжектируемые носители заряда, тем самым снижая вероятность излучательной рекомбинации и, как следствие, мощность излучения. При больших плотностях тока инжекция большого числа носителей заряда приводит к насыщению безызлучательных центров, поэтому различия в мощности излучения, а значит и внешней квантовой эффективности, светодиодов при больших токах гораздо меньше, чем при малых.

Статистический анализ результатов выборочных измерений показал, что величина порогового тока коррелирует со значениями внешней квантовой эффективности светодиода при малых плотностях тока, соответствующих участку роста токовой зависимости внешней квантовой эффективности. Зависимость внешней квантовой эффективности $\eta(j)$ у светодиодов с низким значением порогового тока $I_{t h}=22 \mathrm{nA}$ достигает максимума при плотности тока $0.1 \mathrm{~A} / \mathrm{cm}^{2}$, а у светодиодов с $I_{t h}=607 \mathrm{nA}$ - при $0.6 \mathrm{~A} / \mathrm{cm}^{2}$, при этом абсолютное значение $\eta$ в максимуме зависимости $\eta(j)$ тем больше, чем меньше величина $I_{t h}$ (рис. 2).

Эти результаты позволяют сделать вывод, что чем больше пороговый ток светодиода, тем больше потерь на безызлучательную рекомбинацию в активной области, следовательно, выше концентрация дефектов в активной области светодиода.

Известно, что темп деградации светодиодов InGaN/GaN в процессе испытаний определяется плотностью дефектов в активной области [10]. Для установления связи между значениями порогового тока и скоростью спада мощности излучения светодиодов при работе были проведены их испытания при комнатной температуре на постоянном токе $25 \mathrm{~mA}$ в течение $500 \mathrm{~h}$. Испытания показали, что спад мощности излучения светодиодов с малым пороговым током, находящихся в первом интервале гистограммы распределения (рис. 1), составляет около $5 \%$ относительно исходного значения, а спад мощности излучения

Письма в ЖТФ, 2017, том 43, вып. 4 
светодиодов с большими пороговыми токами, т.е. более дефектных, достигает $30 \%$. Коэффициент корреляции между значениями порогового тока светодиодов и значениями относительного снижения мощности их излучения через $500 \mathrm{~h}$ испытаний составляет 0.9 .

Результаты проведенных исследований показали, что пороговый ток является важным информативным параметром, характеризующим качество светодиодов на основе наногетероструктур InGaN/GaN. Величина порогового тока коррелирует со скоростью спада мощности излучения в процессе испытаний. Чем меньше дефектов в активной области светодиода, являющихся центрами безызлучательной рекомбинации, тем меньше значение порогового тока и скорость спада мощности излучения в процессе эксплуатации. Таким образом, пороговый ток может быть использован для прогнозирования потенциальной степени деградации светодиодов.

Исследование выполнено при финансовой поддержке РФФИ в рамках научного проекта № 16-32-60051 мол_а_дк.

\section{Список литературы}

[1] Nippert F., Karpov S., Pietzonka I. et al. // Jap. J. Appl. Phys. 2016. V. 55. P. 05FJ01.

[2] Meneghini M., Grassa M.la, Vaccari S. et al. // Appl. Phys. Lett. 2014. V. 104. P. 113505.

[3] Шуберт Ф. Светодиоды. М.: Физматлит, 2008.

[4] Аверкиев Н.С., Левинштейн М.Е., Петров П.В. и др. // Письма в ЖТФ. 2009. T. 35. B. 19. C. 97.

[5] Радаев О.А., Сергеев В.А. // Радиоэлектронная техника. 2015. № 2. С. 249.

[6] Radaev O.A., Sergeev V.A., Frolov I.V. // Book of Abstracts of 3rd International School and Conference „Saint Petersburg OPEN 2016“. St. Petersburg, Russia, March 28-30, 2016. St. Petersburg Academic University, 2016.

[7] Королюк В.С., Портенко Н.И., Скороход А.В., Турбин А.Ф. Справочник по теории вероятностей и математической статистике. М.: Наука, Гл. ред. физ.-мат. лит., 1985.

[8] Cunningham J.A. // IEEE Trans. Semicond. Manufact. 1990. V. 3. N 2. P. 60.

[9] Sato H., Ikota M., Sugimoto A., Masuda H. // IEEE Trans. Semicond. Manufact. 1999. V. 12. N 4. P. 409.

[10] Meneghesso G., Meneghini M., Zanoni E. // J. Phys. D: Appl. Phys. 2010. V. 43. P. 354007.

Письма в ЖТФ, 2017, том 43, вып. 4 